\title{
The doctor as human being
}

\author{
Athar Yawar
}

J R Soc Med 2005;98:215-217

There are times when I am not sure whether I am a doctor, a quack or a bit of both. As a psychiatrist, I see patients in the raw. They come believing that they are being pursued by racist thugs; that state secrets are being held in a vault in the Science Museum; that the world is sad and lonely, and that there is no point in living. They bring themselves, haunted by their girlfriends and their pasts, enmeshed in tangled, torn relationships, with all their longings and their fears. The more we get to know our patients, the more we recognize that 'diagnosis' is inadequate; what we have is a human being shaped by time, circumstance, and unseen matters beyond measurement and comprehension.

Usually we offer medication, and some of the time this seems to work. Often it does not; or at least, its contribution is put into shadow by the powers of time and circumstance. And, of course, medication does not address so many of the needs of our patients. It does not attend to a mother's death, or to the crack addicts next door; nor does it satisfy that endless yearning for meaning, understanding and peace. These are all matters that we end up addressing, as doctors; we cannot help but do so, as they are the problems with which our patients present: but we do so implicitly, and often not without a hint of awkwardness.

Why is this? I suppose that at least our regimens of medication are based on a rationale. At some time, under conditions different from those I work under, a different set of patients was given a medication in a series of trials, some of which were reported. The patients felt better, according to selected outcome measures; and so we use the medications. Little is said about what happens when patients stop taking medications, as many of mine seem to do; and occasionally this nags at me in the dark corners of the night. But at least, I am being rational.

By contrast, when it comes to addressing patients' social needs, and their needs for meaning and understanding, there seems precious little science to it. We all know that patients need respect, deserve empathy, and that a good ear is worth a hundred numbers. But these are platitudes.

Athar Yawar, BM MSc, is on a psychiatry rotation based at the Maudsley Hospital, London. His MSc thesis was based on work done at the Medical Foundation for the Care of Victims of Torture.

Helen Bamber Centre, Museum House, 25 Museum Street, London WC1A, UK E-mail: athar.yawar@doctors.org.uk
Experience may help; but it can also entrench bad habits and false assumptions. And yet there is a science involved. We can so often sense when a young girl is hurting, when an old man is in despair; we may be able to direct a glance, a smile or a word that heals the wound before it festers. And this is science at its best - in its original meaning, not of trial and measure, but of knowing. Sometimes, we see, as though with our clearest eyes, the situation and the remedy.

I wonder whether you, in 2055, will have become expert in seeing, glancing at the aspects of the human soul that remain buried under numbers and atoms. The myth of human progress is seductive but often inaccurate, and there is no reason to assume that you will be any wiser and more subtle than we are today. But there are factors that bring me hope.

The first is that the revolution in science associated with Galileo and Francis Bacon has run its course - the vision of science in which the object of study is isolated, its physical circumstances changed, and the outcome measured. By about 1950, it was apparent to physicists that this model worked better under some conditions than others. ${ }^{1}$ In the natural world, objects do not exist in isolation: therefore, this approach does not mimic nature, and to generalize from effects on an object to effects on a system can be hazardous. The forces acting within a system may be so subtle and various that repeatable, measurable outcomes cannot be elicited; however, mathematical patterns may present despite this, including those misleadingly described as 'chaos'. I have a feeling that these patterns will be of considerable use to doctors, allowing the timing and form of intervention to be much more subtle than at present.

Perhaps the best-known incompleteness within the baconian model is the requirement for perfect vision and observer detachment. Can such vision ever be achieved? In any science, what is observed depends upon the state of mind, capacity and perspectives of the observer. Piltdown Man for years went unrecognized as a fake not because the forgery was subtle but because the 'fossil' met certain expectations. And medical scientists can make mistakes as basic as utterly mismeasuring skull sizes, or inventing racial nomenclatures, because of what 'ought' to be there. ${ }^{2}$

If perfect vision is elusive, perfect detachment is impossible. In quantum science the findings are affected by the observer, and matter merges imperceptibily into, perhaps even arises from, consciousness. ${ }^{3}$ This is all the 
more true of medicine. The patient does not exist in isolation. He is a constantly evolving product of the person who is in the role of the doctor and the human being who is presenting himself as the patient. The doctor influences the patient and the patient influences the doctor-not to mention the external forces that come to bear on them both.

Despite its inadequacies, physical science has served medicine well. Or rather, it has served medicine well, insofar as human beings are measurable by physical science. Surgery, which is largely dependent on the material worlds of anatomy and physiology, has saved countless lives. Through the identification of germs, we have been able to treat infectious diseases as physical entities, and some of these appear to have been all but conquered (although it should not be forgotten that the discovery of antibiotics was fortuitous, and immunization was a Near Eastern technique brought to the West by travellers). ${ }^{4,5}$ But human beings have many levels other than the physical, as was noted by a poet and philosopher of several hundred years ago, using terms such as 'mineral', 'animal' and 'man' to describe various concurrent aspects of human operation: ${ }^{6}$

I have experienced seven hundred and seventy moulds. I died from minerality and became vegetable;

And from vegetativeness I died and became animal.

I died from animality and became man.

Then why fear disappearance through death?

Next time I shall die

Bringing forth wings and feathers like angels:

After that soaring higher than angels-

What you cannot imagine. I shall be that.

The less physical the aspect we work with, the less successful our science becomes: until, with the human problems of despair, longing and being out of place, not to mention the need for real personal growth, we are as helpless as our forebears - perhaps more so. As the complexity of human nature exposes the limits of physiology as medicine, we shall be obliged to turn to the other aspects of humanity that have so far lain silent, or perhaps unheeded.

The second reason for suspecting that medicine may evolve into something more complete is that society itself is going through a conceptual crisis - what some philosophers have termed a crisis of grand narratives. ${ }^{7}$ The stories people have used to structure our society and culture are believed in less and less; even the story of our society's essential humanity is being eroded by accounts of torture. ${ }^{8}$ It should be admitted that our society does not necessarily show signs of becoming more thoughtful: the gaps in wealth, opportunity and liberty grow wider day by day across the
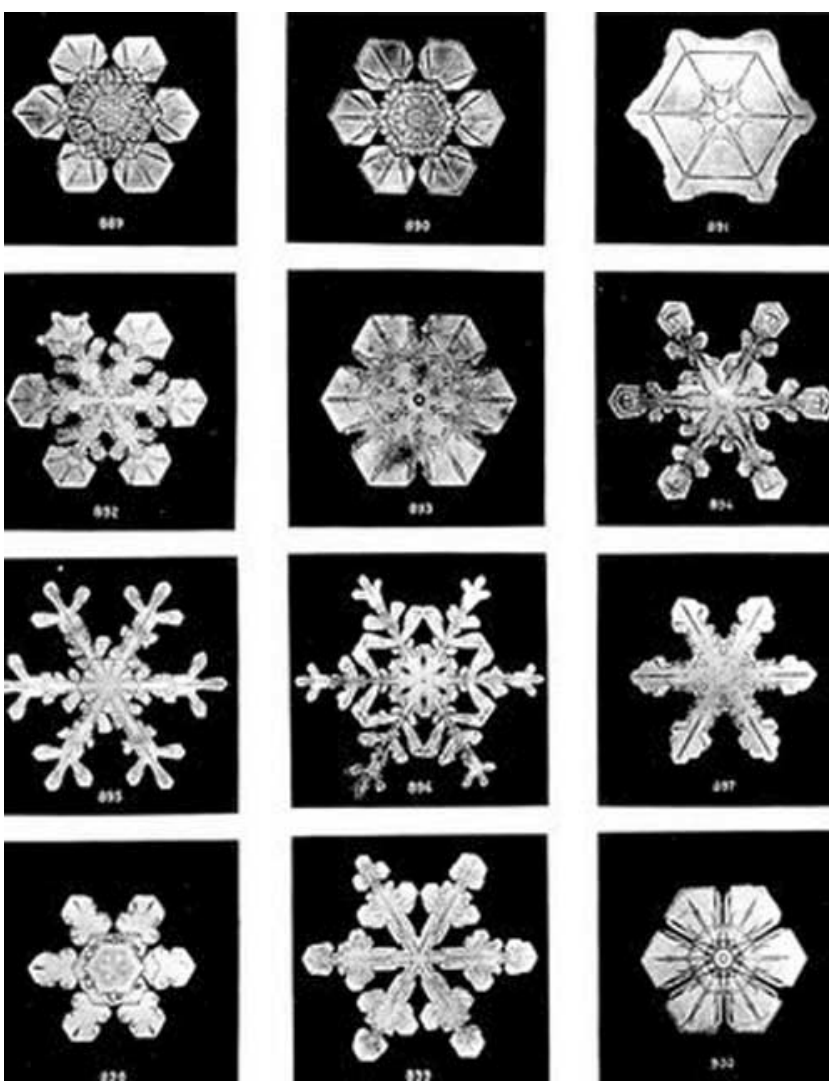

Figure 1 Patterns in nature (Snowflakes by Wilson Bentley, 1902)

the increase. But such imbalances cannot be sustained, and decay is part of renewal. And it may be that, if we can bequeath you in 2055 a planet worth living on, your generation may be free of many of the illusions that held back ours.

We are all in it together - as the human race, and even within the hospital. In fact, it is evident that the notion of 'patient-centred' medicine, while articulating an important and humane concept, is ultimately a fallacy: the patient cannot be separated from his doctor, relationships and surroundings. What we are looking for, it seems to me, is a flow-centred therapy-one where the patient, those associated with the patient, and indeed the doctor, are swept along the path of human development, in what might be called inward evolution. Even in its physical manifestation, illness can be looked upon as an opportunity for renewal and regeneration - as a time when weaknesses have expressed themselves and may be addressed; as the 'night side of life', ${ }^{9}$ during which the body is stilled and strengthened. And all the more so, perhaps, in the realms of the mind, society and meaning. In illness we are brought face to face with our transience; reflection becomes more urgent, and understanding more acute. We doctors are uniquely privileged in this respect: every day, during the 
most mundane of our work, we are exposed to people defining and stumbling their way to being human.

A science of human understanding and development cannot neglect the question of what human beings are developing towards. This essay is not the place for a full discussion, but a basic prerequisite, if human beings are to live and grow together, is generosity, with compassion as a generosity of the spirit. But because misdirected generosity can lead to danger, what is needed for everyday practice is wisdom - the ability to apply compassion well. I suppose that if compassion is water, then a good doctor is a gardener - knowing not only when and where to direct the water and how, but which plants to uproot and which to foster. How is this knowledge acquired? Perhaps the first step, for all of us, is to make the most of what we have. This involves what might be called transparency. First, we must become transparent to our knowledge - seeing what we really see and not what we assume that we should have seen, taking in what will actually affect the patient's life and not what our textbooks instil. Part of this will involve avoiding the treachery of labels. It is so easy to confuse the container with the content; and being able to see what is there, despite all the labels and assumptions that have been applied, must be one of the first steps towards knowledge. ${ }^{10}$ The more one knows, the more one realizes how little one conceives, and how infinitely vast and beautiful that world of knowledge is.

The second step would be to become transparent to ourselves - in relation to our aims, the way that we do things, and our strengths and weaknesses. We are all good in some ways and not so good in others. ${ }^{11}$ Our weaknesses can so easily be disguised by evolving surrogate aims, by claiming that the possible is impossible, or by allowing shortcomings to masquerade as definitions of identity. I suppose a doctor is someone who is willing to do whatever is necessary, within the constraints of the environment and the system within which he works, bearing in mind the rights of people outside the hospital and his own need to be fresh, able and secure. Indeed, if we are to develop as doctors capable of sensing patterns within ourselves and others, and to work effectively with these patterns, we ourselves must develop as human beings: bringing all the richness of varied, subtle and even compassionate lives to the clinic and to the hospital. If compassion is water, humanity may be likened to sunlight, that can brighten even the dingiest ward, on the most treacherous Monday afternoon.

\section{REFERENCES}

1 Peat FD. From Certainty to Uncertainty. Washington DC: Joseph Henry Press, 2002

2 Littlewood R, Lipsedge M. Aliens and Alienists. Harmondsworth: Penguin, 1982

3 Bohm D. Wholeness and the Implicate Order. London: Routledge, 1980

4 Le Fanu J. The Rise and Fall of Modern Medicine. London: Little, Brown, 1999

5 Montagu MW. The Turkish Embassy Letters. London: Virago, 1994

6 Shah I. The Way of the Sufi, 2nd edn. London: Octagon Press, 1980

7 Lyotard J. The Postmodern Condition: A Report on Knowledge. Manchester: Manchester University Press, 1984

8 Sontag S. What have we done? Guardian 24 May 2004

9 Sontag S. Illness as Metaphor; AIDS and its Metaphors. Harmondsworth: Penguin, 1991

10 Shah I. The Book of the Book. London: Octagon Press, 1969

11 Collier J, Longmore M, Duncan Brown T, eds. The last page. Oxford Handbook of Clinical Specialties, 5th edn. Oxford: OUP, 1999 